\title{
STUDY ON THE OPTIMUM SIZE OF RAILWAY SLEEPER FOR BALLASTED TRACK
}

\author{
Akira NAMURA $^{1}$, Yukihiro KOHATA ${ }^{2}$ and Seiichi MIURA ${ }^{3}$ \\ ${ }^{1}$ Member of JSCE, Senior Researcher, Railway Dynamics Division, Railway Technical Research Institute \\ (2-8-38, Hikari-cho, Kokubunji, Tokyo 185-8540, Japan) \\ E-mail: lustigan@rtri.or.jp \\ ${ }^{2}$ Member of JSCE, Associate Professor, Dept. of Civil Eng., Muroran Institute of Technology \\ (27-1, Mizumoto-cho, Muroran, Hokkaido 050-8585, Japan) \\ E-mail:kohata@news3.ce.muroran-it.ac.jp \\ ${ }^{3}$ Fellow Member of JSCE, Professor, Faculty and Graduate School of Eng., Hokkaido University \\ (Kita 8 Nishi 5, Sapporo, Hokkaido 060-8628, Japan) \\ E-mail: s-miura@eng.hokudai.ac.jp
}

\begin{abstract}
This paper discusses the effects of sleeper size on cyclic deformation properties of railway ballast under the cyclic loading. Two-dimensional FE linear elastic analyses were performed in order to investigate the effects of sleeper size on the stress distribution in the ballasted track. Based on the results of FE analyses, a series of full-scale cyclic loading tests were performed by using various sleepers of different lengths and heights. It is found that the track settlement in the state where a clearance gap exists between sleeper and ballast can be estimated by amount of displacement amplitude up to a full contact and a maximum displacement rate of sleeper.
\end{abstract}

Key Words : track settlement, cyclic loading, full- scale model test, maintenance

\section{INTRODUCTION}

The ballast composed of uniformly graded crushed gravel is used for railway tracks for its angularity, adequate stiffness, ease of repair and so on. However, differential settlement arises in the track due to the movement or deterioration (abrasion, crushing, etc.) of ballast particles under cyclic train loads.

Generally, a stability of running motion of vehicle is impaired by increased track irregularities and the ride comfort for passengers by intensified vehicle vibration. The risk of train derailment arises by larger inertial force due to the vehicle vibration when the track irregularity further progresses. Therefore, maintenance standard for track irregularity has been established. When a track irregularity is found to have exceeded a certain constant baseline by regular monitoring, maintenance is performed to restore the depleted track condition. In the standard of ballasted track, a method of judging the validity of the assumed track structure is adopted to compare between an acceptable value of track irregularity growth based on prescribed conditions, which are a running motion property of vehicle (running safety, ride comfort) or a maintenance cycle etc., and an estimated value of track irregularity growth obtained from various conditions, which are a track structure, a vehicle and an running speed/interval. This is one of features in the standard of ballasted track. Therefore, the design of ballasted track is different from the general design of structure in civil engineering. It is considered that the design concept is appropriate to the present condition requested for both the speed-up of trains and the laborsaving of maintenance ${ }^{1)}$. However, in order to design a rational track structure in the present aim for a more flexible track structure when a track structure is diversified, it is necessary to develop a method to estimate precisely a ballast settlement, which is a main factor of a track irregularly among various design conditions.

Authors have performed a series of cyclic loading tests, focusing the attention on a median loading amplitude and a value of loading amplitude on the 
full-scale ballasted model track that is assumed to exist on the rigid roadbed on viaducts etc., in order to improve the accuracy of a predictive equation for amount of ballast settlement, and have discussed the cyclic deformation properties of ballast and that evaluation method ${ }^{2), 3)}$. In these studies, it was found that a settlement tended to increase with a cyclic loading when a minimum load was small. A transition of displacement amplitude for each measure point (sleeper ends and center) was investigated, and it was found that the differential of displacement amplitude between a sleeper end and center increased as a displacement amplitude of sleeper end increased gradually with the cyclic loading. This phenomenon was considered as a change of sleeper support state, that is, the support position of sleeper moved to a center of sleeper from a position right under a rail just after tamping due to the cyclic loading. It was considered that a small clearance gap arose between the bottom of sleeper right under a rail and the top of ballast, and the differential of displacement amplitude between the sleeper end and center became large. A possibility was considered that a sleeper stiffness and length contributed to this phenomenon.

Sussmann et al. ${ }^{4)}$ also have pointed to an inconsistent rail deflection due to the central support of sleeper in the cause of track irregularities.

For this paper, several types of sleeper of different lengths and heights were produced based on the results of two-dimensional FE linear elastic analysis aiming at finding countermeasures to reduce track settlements due to cyclic loading in the ballasted track on the rigid roadbed for viaducts etc. A series of cyclic loading tests were performed on a full-scale model track composed of produced sleepers, and the influence of the sleeper shape on cyclic deformation property of railway ballast was discussed.

\section{CONVENTIONAL RESEARCH ON SLEEPER SHAPE}

The roles of sleeper on a ballasted track are as follows; 1) it should be able to install rails easily and has large retentive force in order to sustain positions of the rail, especially, the constant rail gauge, 2 ) it has enough strength to endure train loads and it should distribute widely train loads to ballast, 3) it gives a track the buckling resistance force, 4) it achieves necessary electric insulation between two rails, etc. About the role to distribute widely train loads to ballast among the above-mentioned, the study concerning a sleeper shape is very few. There is an examination example in the first stage of PC sleeper development in the 1950s from a design side and track settlement.

\section{(1) Sleeper shape and design ${ }^{5)}$}

It is assumed that it is necessary to consider the following points in the design of sleeper shape size.

\section{a) Length}

The sleeper length has a great influence on the sleeper bending moment. In general, the absolute value of negative bending moment at a sleeper center decreases as the sleeper becomes long. It might become finally a positive bending moment. The influence of the positive bending moment increases gradually at a position right under a rail. Therefore, a PC sleeper length should be determined so that the bending moment of sleeper center balances that of sleeper right under the rail.

\section{b) Height}

It is necessary to enlarge a height to increase a sleeper weight and a longitudinal and lateral resistance within ballast. However, this increases the sleeper price due to the increase of a necessary concrete amount, and also increases a necessary amount of ballast, therefore it becomes uneconomical. Moreover, when the height of sleeper increases, it becomes easy to cause a torsional failure.

\section{(2) Sleeper shape and track settlement}

There is a study concerning a shape effect of wooden and concrete sleeper performed by Okabe et al. In their study, the static and cyclic loading tests were performed on the 20 types of concrete sleepers of different lengths $(2.0,2.1,2.2$ and $2.3 \mathrm{~m})$, heights $(120-180 \mathrm{~mm})$ and widths $(180-280 \mathrm{~mm})$. The following conclusions were shown. When a bottom area of sleeper increases, it is more advantageous to increase a length than a width to inhibit a track settlement. A result was obtained that it is necessary to give sleeper flexibility by means of making the sleeper in a long and slender shape, because the stiffness of concrete sleeper is originally too much.

\section{(3) Current situation}

A cross section of pretensioning prestressed concrete sleeper - Type 3 is shown in Fig. ${ }^{6}$, which is used generally at a straight track of a conventional line of the Japan Railways. This sleeper dimension was standardized in 1961. Since a PC sleeper was expensive compared to a wooden sleeper, it seems that a sleeper length was decided to $2.0 \mathrm{~m}$ in consideration of only a minimum anchorage length of a PC steel wire, $40 \mathrm{~cm}$. This minimum length is the 


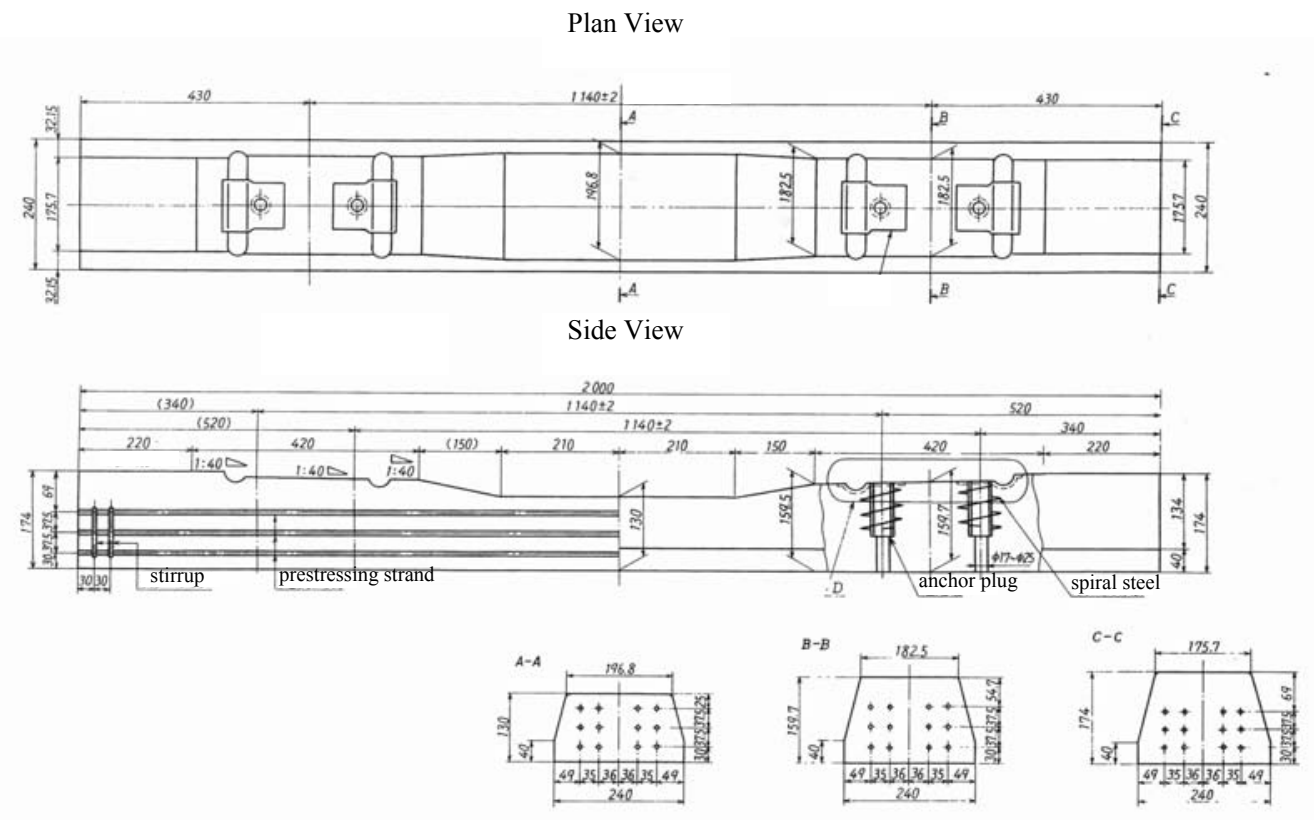

Fig. 1 Pretensioning prestressed concrete sleeper - Type ${ }^{6)}$

length to be able to apply a necessary prestress to a cross section under a rail where a bending moment by a load reaches a maximum value. The length in a sleeper developed afterwards for conventional lines is almost same as the sleeper developed in 1961. A sleeper height was produced originally from 140 $\mathrm{mm}$, which was a same degree of height as a wooden sleeper, in consideration of a renewal from wooden sleepers. However, it has been produced up to about $230 \mathrm{~mm}$ in height due to a buckling stability of continuous welded rail track and a countermeasure for lateral load at a sharp curve.

From the above, it is found that the findings concerning the sleeper shape and track settlement are not reflected in the design of present sleeper.

\section{STRESS DISTRIBUTION ANALYSIS IN RAILWAY BALLAST}

According to the results of large triaxial cyclic test on ballasts ${ }^{7}$, the resilient axial strains in cyclic loading are less than $0.5 \%$ except an initial portion of cyclic loading. The ballast can be treated as an elastic material in the macro scale since an increment of residual axial strain by loading of one time is a little and a hysteresis loop closes. On the other hand, it is considered that a shear deformation is a main part on a deformation behavior in a progressive settlement process of ballast at an actual track.

In this chapter, a maximum shear stress distribution in ballast related closely to a shear deformation

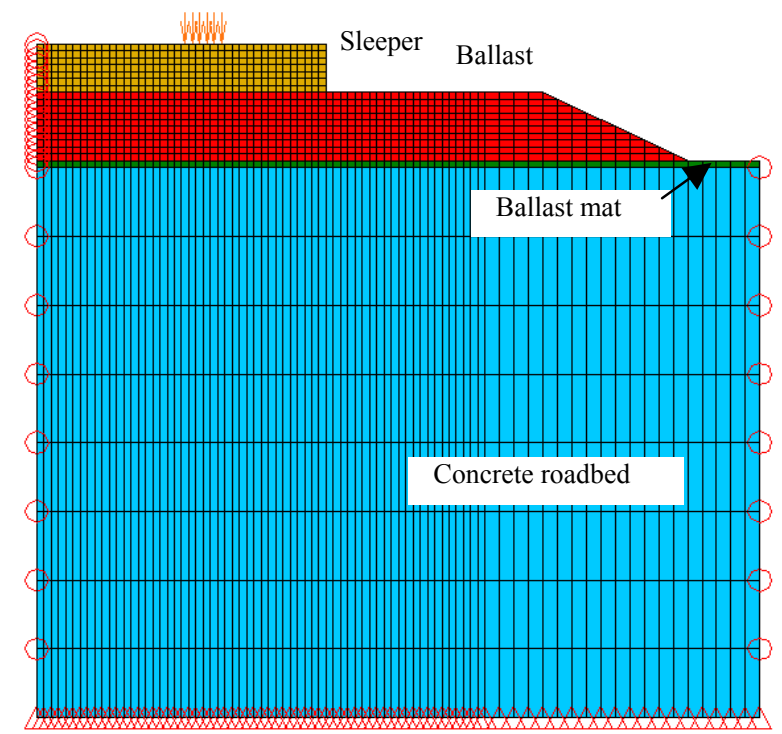

Fig. 2 2D FEA model

is described by FE linear elastic analysis, and a sleeper shape is discussed with a restraint of track settlement.

\section{(1) Analytical method}

\section{a) Analytical model}

The FE linear elastic analysis was performed by 2D plane strain model as shown in Fig.2. The model is an axisymmetric 1/2 model against a center axis of sleeper. The section shape of PC sleeper in a length direction is not constant and a center part of sleeper is a concave shape as shown in Fig.1. In this paper, since it is not aimed at a detailed design of sleeper, a sleeper shape was assumed as a rectangular solid for the simplification. The ballasts are filled 
Table 1 Material parameters

\begin{tabular}{|l|r|r|}
\hline & E (Mpa) & \multicolumn{1}{c|}{ v } \\
\hline Sleeper & 35000 & 0.17 \\
\hline Ballast & 88 & 0.28 \\
\hline Ballast mat & 1.125 & 0.49 \\
\hline Concrete roadbed & 35000 & 0.17 \\
\hline
\end{tabular}

up to the top of sleeper at sleeper ends in an actual track. If the ballast in this part is modeled as a continuum, a tensile stress not caused actually acts between sleeper ends and ballasts. Therefore, only the ballast below the bottom of sleeper was modeled.

\section{b) Material parameters of element}

The elements of model were composed of a PC sleeper, ballast, a ballast mat and a concrete roadbed. The material parameters are used as shown in Table $\mathbf{1}^{8), 9)}$. The value of Young's modulus and Poisson's ratio was used by assuming the value at an average stress level (100 kPa) caused in an actual track based on results of large triaxial test.

\section{c) Confined condition}

A horizontal direction was fixed at a centerline and an end of concrete roadbed, and it was assumed as a complete fixation at the bottom of model.

\section{d) Loading condition}

The uniformly distributed stress was applied on a sleeper right under rails. A vertical stress per rail was used a value divided $10 \mathrm{kN}$ as a unit load by the contact area $(150 \mathrm{~mm} \times 240 \mathrm{~mm})$ between rail and sleeper. For ballast, an influence of self-weight is smaller than a loaded weight as it is possible to disregard, and the analytical method is a linear elastic analysis. Therefore, the self-weight is not considered as a loading condition.

\section{e) Analytical condition}

Analyses were performed for 75 cases as 3 depths of ballast $\left(\mathrm{h}_{\mathrm{B}}\right)(150,250$ and $350 \mathrm{~mm}), 5$ lengths of sleeper $(l)(1.8,2.0,2.2,2.4$ and $2.6 \mathrm{~m})$ and 5 heights of sleeper $\left(\mathrm{h}_{\mathrm{S}}\right)(35,70,105,175$ and $245 \mathrm{~mm})$. The standard section of ballasted track at a straight part of conventional line of the JR is as follows; a ballast depth is $h_{B}=250 \mathrm{~mm}$, a sleeper length is $l=2.0 \mathrm{~m}$ and a sleeper height is $\mathrm{h}_{\mathrm{S}}=175$ $\mathrm{mm}$. This standard section is used when an analytical result is normalized in the next section.

\section{(2) Analytical results}

Analytical results are discussed by vertical displacements for the top of ballast (D) and maximum shear stresses $\left(\tau_{\max }\right)$.

\section{a) Vertical displacement (D)}

A distribution of vertical displacement for the top of ballast is shown in Fig.3 when the $l$ is different. In the case of $h_{S}=175 \mathrm{~mm}$ (Fig.3 (a)), it is found that $D$ right under a rail is larger than $D$ at a sleeper center when $l$ is short, and D right under a rail and at a sleeper end is smaller than $D$ at a sleeper center when $l$ is long. In the case of $h_{S}=35$ mm (Fig.3 (b)), D indicates a maximum value right under a rail regardless of $l$. It is found that a shape of distribution is drawn as a shape applied directly uniformly distributed load on the top of ballast. A relationship between a shape of sleeper and $D_{\max } /$ $D_{0, \max }$ is shown in Fig.4, where $D_{\max }$ is a maximum value of vertical displacement for the top of ballast and this value is normalized by $\mathrm{D}_{0, \max }=0.15 \mathrm{~mm}$ on the standard section (refer to bold line in Fig.3 (a)) in this figure. An influence of $l$ is a little though $\mathrm{D}_{\max }$ increases when $\mathrm{h}_{\mathrm{S}}$ is low.

\section{b) Maximum shear stress in ballast}

An analytical result at a point of stress concentration depends on the element mesh size of an FE analysis, however discussions are carried out by assuming that reliability exists here in the solution.

$\tau_{\max }$ is shown in Fig.5 when $\mathrm{h}_{\mathrm{S}}$ is different and $\tau_{\max }$ is shown in Fig.6 when $l$ is different. From Fig.5, it is found that a distribution of $\tau_{\max }$ moves from a position right under a rail to a position of a sleeper end with an increase of $h_{S}$. From Fig.6, it is found that the $\tau_{\max }$ at a sleeper end when $l$ is short decreases with an increase of $l$.

A relationship between a shape of sleeper and $\left(\tau_{\max }\right)_{\max } /\left(\tau_{0, \max }\right)_{\max }$ is shown in Fig.7, where $\left(\tau_{\max }\right)_{\max }$ is a maximum value of $\tau_{\max }$ in a section for each analysis case and this value is normalized by a maximum value $\left(\tau_{0, \max }\right)_{\max }=41 \mathrm{kPa}$ in a standard section (refer to Fig.5 (d) and Fig.6 (b)) in this figure. When an $\mathrm{h}_{\mathrm{S}}$ is low, $\left(\tau_{\max }\right)_{\max }$ arises right under a rail. Since $\tau_{\max }$ right under a rail decreases with an increase of $h_{S}$, $\left(\tau_{\max }\right)_{\max }$ decreases also, on the other hand, since $\tau_{\max }$ at a sleeper end increases, $\left(\tau_{\max }\right)_{\max }$ increases again from a certain $h_{S}$. Moreover, when $\mathrm{h}_{\mathrm{S}}$ is high, it is found that $\left(\tau_{\max }\right)_{\max }$ decreases due to an increase of $l$.

Since a distribution of $\tau_{\max }$ is different due to a shape of sleeper, a relation between $h_{S}$ and $\tau_{\max }$ was investigated by paying attention to $\tau_{\max }$ in the top of ballast right under a rail (point $A$ ), in the bottom of ballast right under a rail (point $B$ ) and in the top of ballast at a sleeper end (point $C$ ) for each sleeper shape (Fig.8). It is found that $\tau_{\max }$ at a point $A$ and $B$ decreases as $h_{S}$ increases, and $\tau_{\max }$ at a point $C$ increases. An intersection in these lines is $h_{S}$ in which $\tau_{\max }$ is minimized. That is, $\tau_{\max }$ in ballast is minimized if $h_{S}$ is set up about $90 \mathrm{~mm}$ for $h_{B}=250 \mathrm{~mm}$ and $l=2.0 \mathrm{~m}$. The $\tau_{\max }$ is about $70 \%$ for $\mathrm{h}_{\mathrm{S}}=175$ $\mathrm{mm}$ in the standard section. 


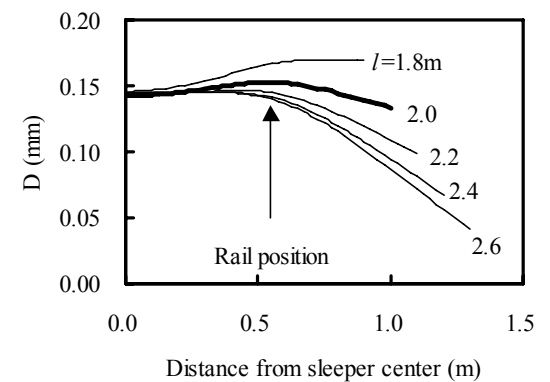

(a) $\mathrm{h}_{\mathrm{B}}=250 \mathrm{~mm}, \mathrm{~h}_{\mathrm{S}}=175 \mathrm{~mm}$

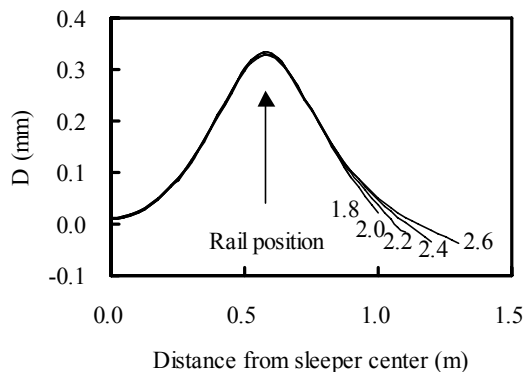

(b) $\mathrm{h}_{\mathrm{B}}=250 \mathrm{~mm}, \mathrm{~h}_{\mathrm{S}}=35 \mathrm{~mm}$

Fig. 3 Distribution of vertical displacement for the top of ballast

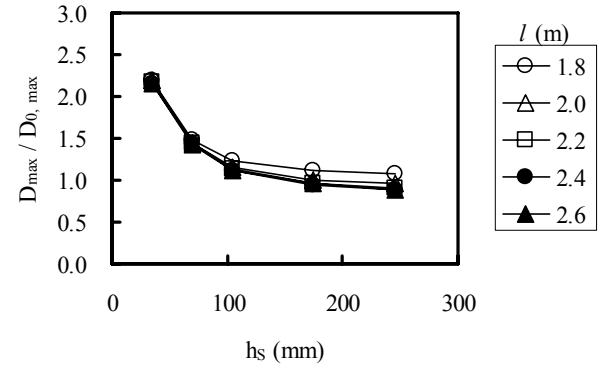

Fig. 4 Relation between sleeper shape and

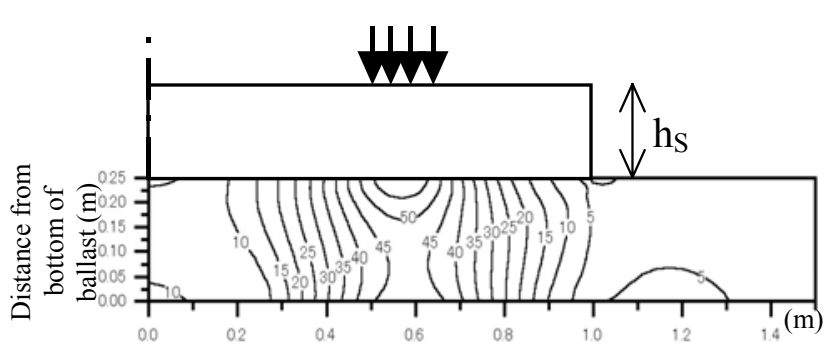

(a) $\mathrm{h}_{\mathrm{S}}=35 \mathrm{~mm}$

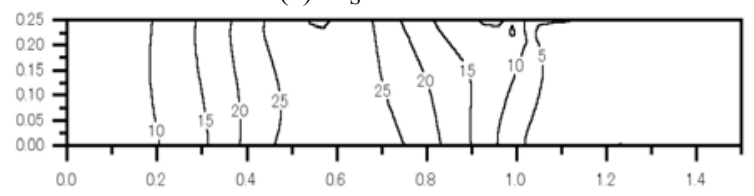

(b) $\mathrm{h}_{\mathrm{S}}=70 \mathrm{~mm}$

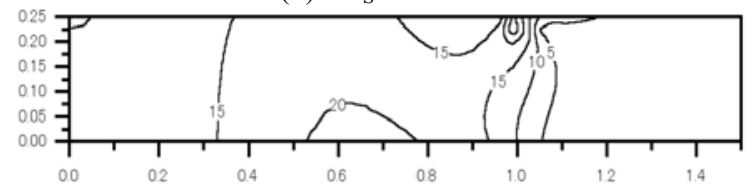

(c) $h_{\mathrm{S}}=105 \mathrm{~mm}$

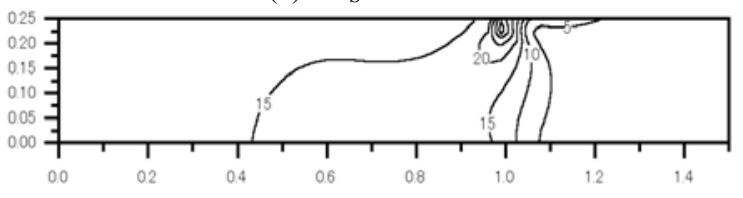

(d) $\mathrm{h}_{\mathrm{s}}=175 \mathrm{~mm}$

Fig. 5 Distribution of $\tau_{\max }$ when $h_{S}$ is different $(l=2.0 \mathrm{~m})$

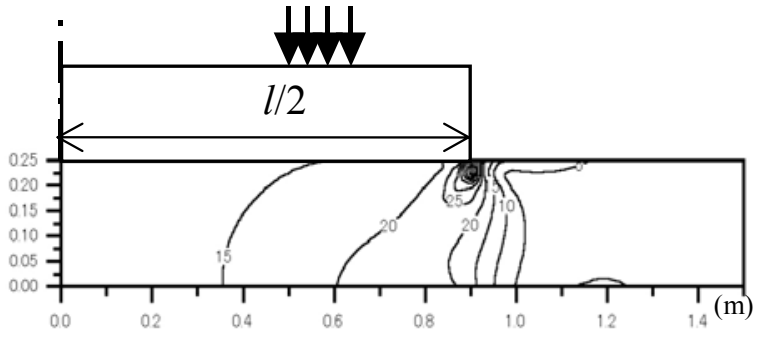

(a) $l=1.8 \mathrm{~m}$

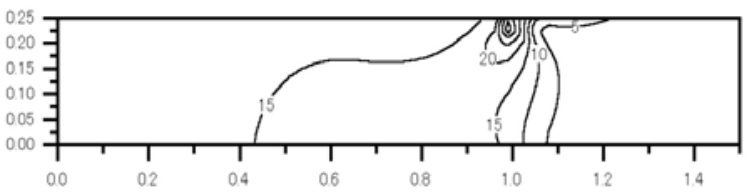

(b) $l=2.0 \mathrm{~m}$

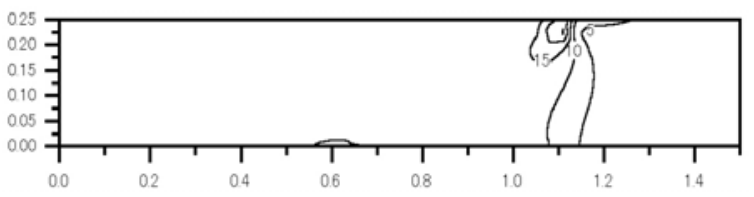

(c) $l=2.2 \mathrm{~m}$

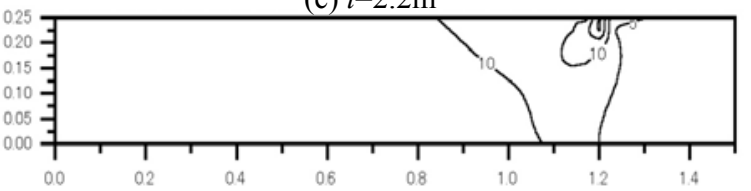

(d) $l=2.4 \mathrm{~m}$

Fig. 6 Distribution of $\tau_{\max }$ when $l$ is different $\left(\mathrm{h}_{\mathrm{S}}=175 \mathrm{~mm}\right)$

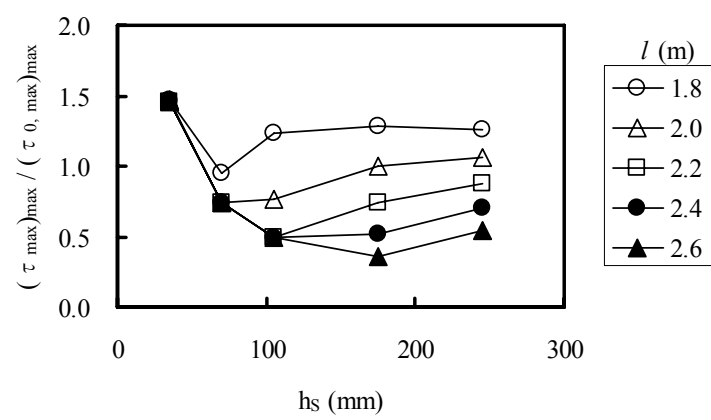

Fig. 7 Relation between sleeper shape and $\tau_{\max }$ $\left(\mathrm{h}_{\mathrm{B}}=250 \mathrm{~mm}\right)$

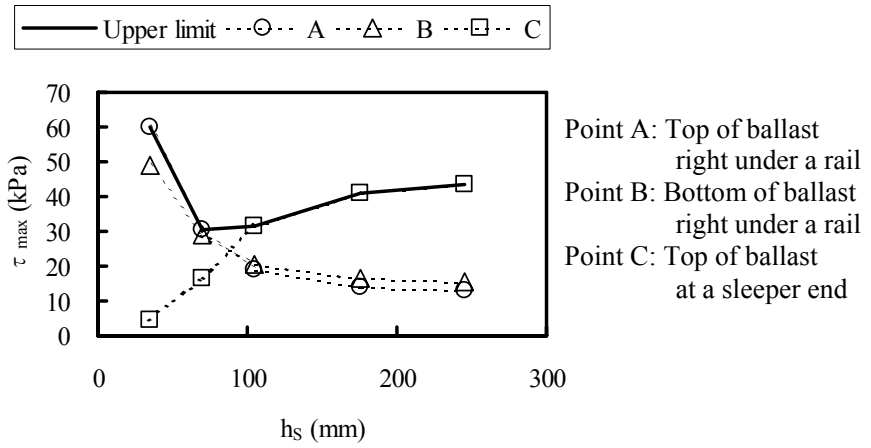

Fig. 8 Relation between sleeper shape and $\tau_{\max }$ at each point $\left(\mathrm{h}_{\mathrm{B}}=250 \mathrm{~mm}, l=2.0 \mathrm{~m}\right)$ 


\section{SLEEPER PRODUCTION FOR CYCLIC LOADING TEST}

From 2D linear elastic FE analysis, it is found that $\tau_{\max }$ in ballast is minimized by setting up about the half of $h_{S}=175 \mathrm{~mm}$ in the standard section for $\mathrm{h}_{\mathrm{B}}=250 \mathrm{~mm}$ in a ballast depth and $l=2.0 \mathrm{~m}$ in a sleeper length. And also, it is found that $\tau_{\max }$ in ballast decreases by increasing a sleeper length for the standard height of sleeper. Then, the synthetic sleeper ${ }^{10)}$ was made which consists of hard type polyurethane foam and continuous long glass fiber with a shape shown in Table 2. The reason, why this material is selected, is that this material is formed easily into many different shapes compared with a concrete sleeper and that the quality is steady compared with a wooden sleeper. However, because the Young's modulus of synthetic sleeper is about $1 / 3$ of a concrete sleeper, the height of synthetic sleeper was increased to about 1.5 times of a height of concrete sleeper to homologize to a bending rigidity.

\section{CYCLIC LOADING TEST ON SLEEPER SHAPE}

\section{(1) Test track}

Fig.9 shows a cross section of test track. To prevent a distribution of load to adjacent sleepers due to track skeleton rigidity, a loaded weight was applied by one sleeper in each test case. Ballast was constructed according to following procedures as same as an actual maintenance work. First of all, the ballast was prepared to a shape of a prescribed section, the compaction was performed by a plate compactor and the sleeper was installed. After that, the track was regulated by tamping ballast right under a rail by using a tamping tool and by compacting a shoulder of ballast by using a plate compactor. Before starting each test, the above track maintenance was performed to reduce an influence of last test. The ballast used for a test was a crushed stone of andesite produced at Otsuki city in Yamanashi Prefecture, and it was used under air dried condition.

\section{(2) Loading condition}

In the test, a vertical load was applied directly to both rails. A vertical load for each rail was determined by assuming an actual train load and axle arrangement. Moreover, $\mathrm{P}_{\max }=45 \mathrm{kN}$ and $\mathrm{P}_{\min }=2$ $\mathrm{kN}$ were selected as maximum and minimum vertical load respectively in consideration of an effect of load distribution due to track skeleton rigidity. First of all, cyclic loadings of 10 times were performed by loading and unloading up to a $\mathrm{P}_{\max }$. A loading rate was $1 \mathrm{kN} / \mathrm{sec}$. After that, a sinusoidal cyclic loading was performed by a frequency of $2 \mathrm{~Hz}$ for more than $2 \times 10^{5}$ cycles.

\section{(3) Test results}

\section{a) Difference in sleeper deflection}

A difference in displacement amplitude of sleeper on a cyclic loading was shown in Fig.10, and a difference in sleeper settlement at a $\mathrm{P}_{\max }$ on a cyclic loading was shown in Fig.11. For $l=2.0 \mathrm{~m}$ in a sleeper length, a differential settlement is caused at locations of both rails due to the increase of displacement amplitude at a sleeper end according with cyclic loading (Fig.10 (a)-(c) and Fig. 11 (a)-(c)). For $l=2.6 \mathrm{~m}$ in a sleeper length, a difference in displacement amplitude is small at both ends of sleeper whereas displacement amplitude at a sleeper center increases according with cyclic loading, and it is found that the sleeper settles down equally (Fig.10 (g)-(i) and Fig. 11 (g)-(i)). For $l=2.3 \mathrm{~m}$ in a sleeper length, a transition in deflection shapes is different depending on the $\mathrm{h}_{\mathrm{S}}$. For $\mathrm{h}_{\mathrm{S}}=130 \mathrm{~mm}$, there is little difference in displacement amplitude from an initial portion of cyclic loading, and the sleeper settles down gradually and equally (Fig.10 (d) and Fig. 11 (d)). For $\mathrm{h}_{\mathrm{S}}=195 \mathrm{~mm}$, displacement amplitude at both ends of sleeper is small whereas displacement amplitude at a sleeper center increases according with cyclic loading, and the sleeper settles down equally (Fig.10 (e) and Fig. 11 (e)). For $h_{S}=$

Table 2 Sleeper size for test

\begin{tabular}{|c|c|c|}
\hline Width & Heigtht $h$ & Length $l$ \\
\hline \multirow{7}{*}{240} & 130 & \multirow{3}{*}{2000} \\
\cline { 2 - 2 } & 195 & \\
\cline { 2 - 2 } & 260 & \\
\cline { 2 - 2 } & 130 & \multirow{3}{*}{2300} \\
\cline { 2 - 2 } & 195 & \\
\cline { 2 - 2 } & 260 & \\
\cline { 2 - 2 } & 130 & \multirow{3}{*}{2600} \\
\hline & 195 & \\
\hline & 260 & \\
\hline
\end{tabular}

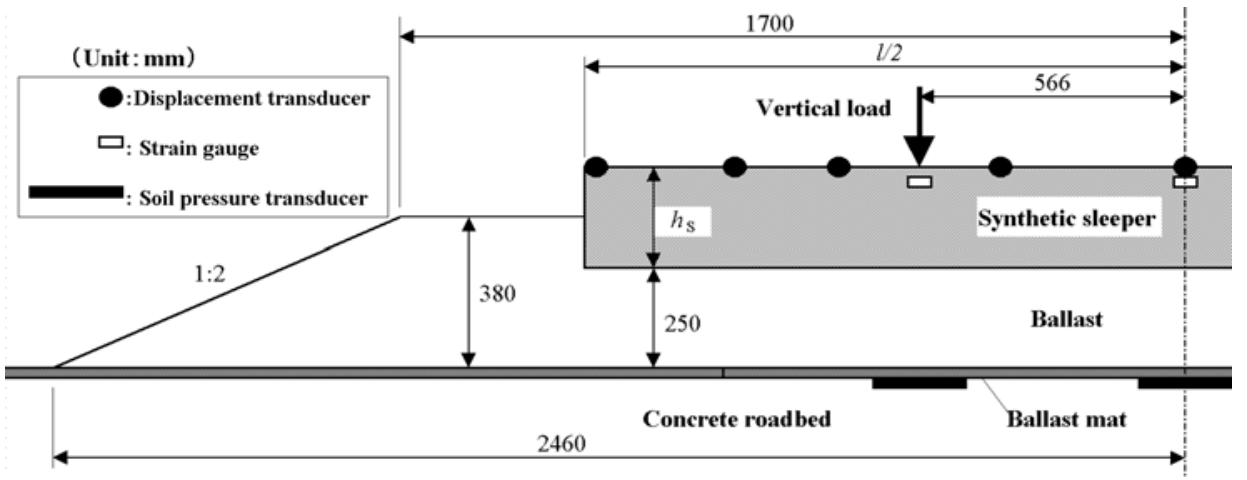

Fig. 9 Cross section of test track 
Distance from sleeper center (m)

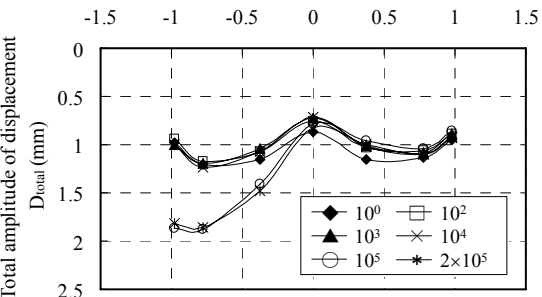

(a) $l=2.0 \mathrm{~m}, \mathrm{~h}_{\mathrm{S}}=130 \mathrm{~mm}$

Distance from sleeper center $(\mathrm{m})$

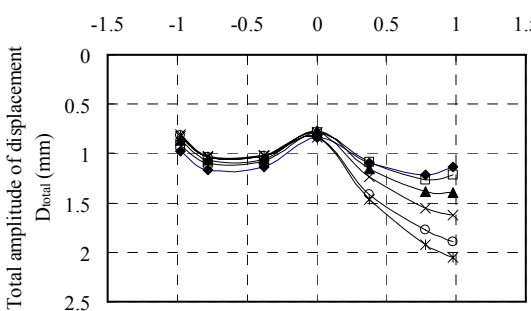

(b) $l=2.0 \mathrm{~m}, \mathrm{~h}_{\mathrm{S}}=195 \mathrm{~mm}$

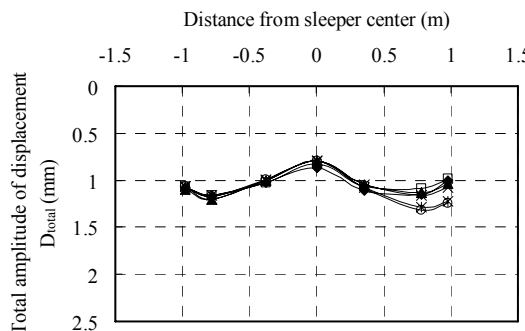

(c) $l=2.0 \mathrm{~m}, \mathrm{~h}_{\mathrm{S}}=260 \mathrm{~mm}$
Distance from sleeper center (m)

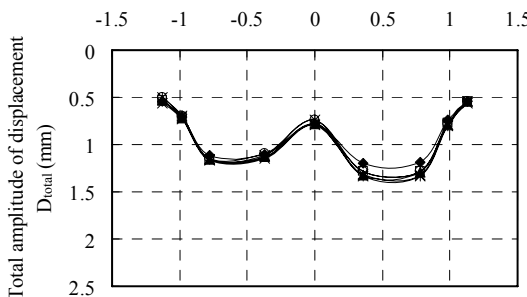

(d) $l=2.3 \mathrm{~m}, \mathrm{~h}_{\mathrm{S}}=130 \mathrm{~mm}$

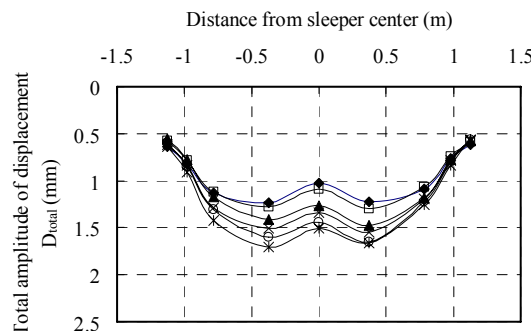

(e) $l=2.3 \mathrm{~m}, \mathrm{~h}_{\mathrm{S}}=195 \mathrm{~mm}$

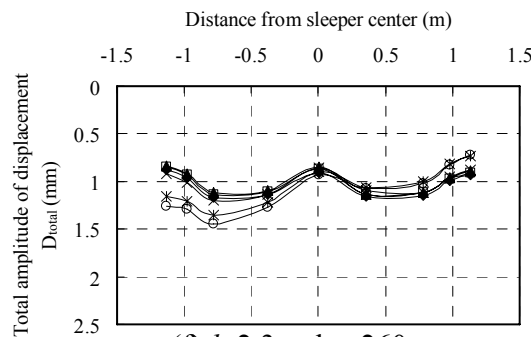

(f) $l=2.3 \mathrm{~m}, \mathrm{~h}_{\mathrm{S}}=260 \mathrm{~mm}$
Distance from sleeper center (m)

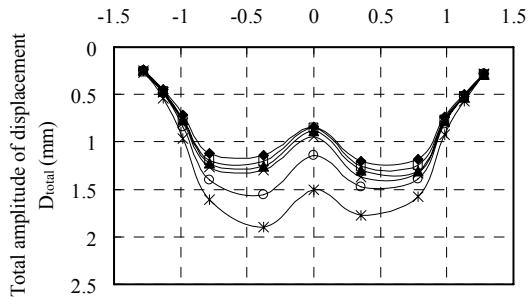

(g) $l=2.6 \mathrm{~m}, \mathrm{~h}_{\mathrm{S}}=130 \mathrm{~mm}$

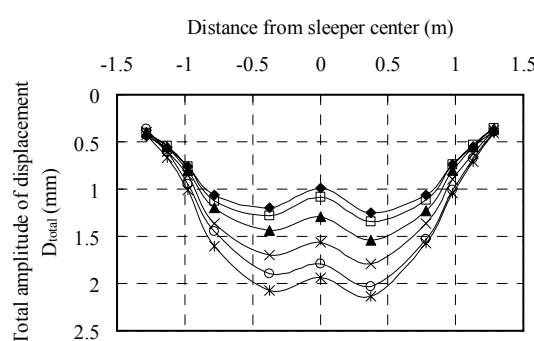

(h) $l=2.6 \mathrm{~m}, \mathrm{~h}_{\mathrm{S}}=195 \mathrm{~mm}$

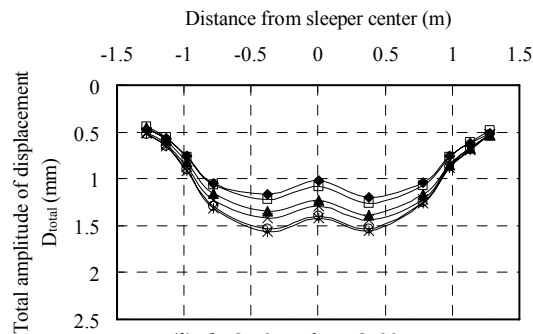

(i) $l=2.6 \mathrm{~m}, \mathrm{~h}_{\mathrm{S}}=260 \mathrm{~mm}$

Fig. 10 Transition of total amplitude of displacement

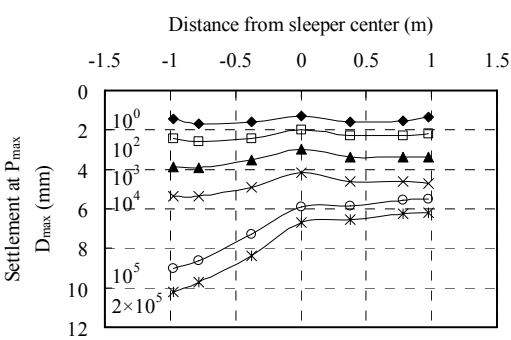

(a) $l=2.0 \mathrm{~m}, \mathrm{~h}_{\mathrm{S}}=130 \mathrm{~mm}$

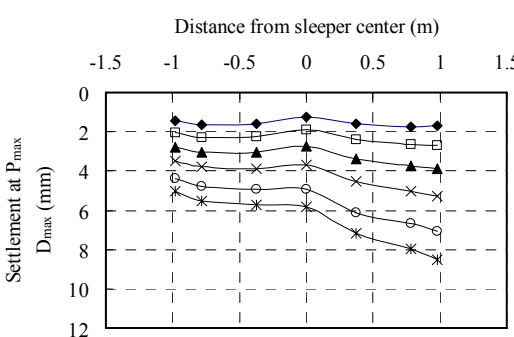

(b) $l=2.0 \mathrm{~m}, \mathrm{~h}_{\mathrm{S}}=195 \mathrm{~mm}$

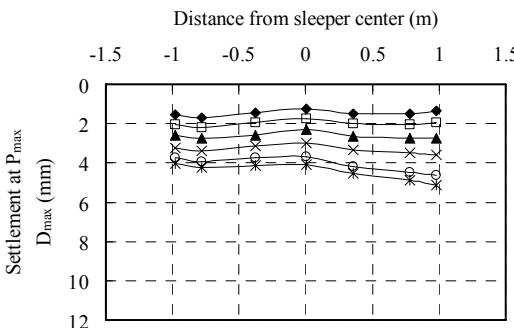

(c) $l=2.0 \mathrm{~m}, \mathrm{~h}_{\mathrm{S}}=260 \mathrm{~mm}$

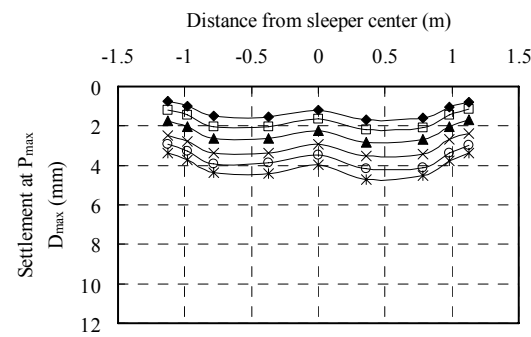

(d) $l=2.3 \mathrm{~m}, \mathrm{~h}_{\mathrm{S}}=130 \mathrm{~mm}$

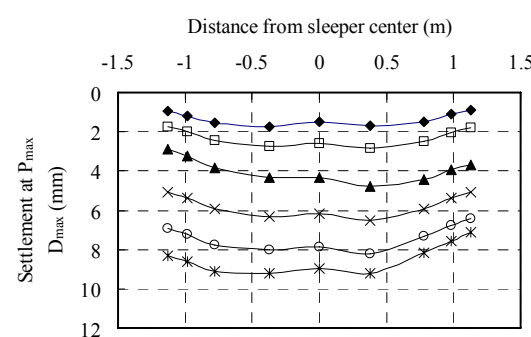

(e) $l=2.3 \mathrm{~m}, \mathrm{~h}_{\mathrm{S}}=195 \mathrm{~mm}$

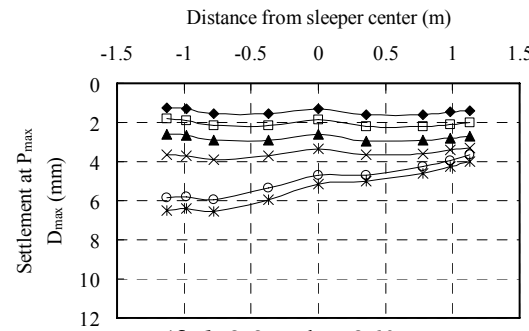

(f) $l=2.3 \mathrm{~m}, \mathrm{~h}_{\mathrm{S}}=260 \mathrm{~mm}$

Fig. 11 Transition of settlement at $P_{\text {max }}$

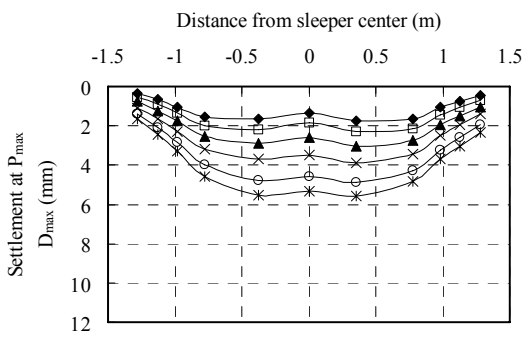

(g) $l=2.6 \mathrm{~m}, \mathrm{~h}_{\mathrm{S}}=130 \mathrm{~mm}$

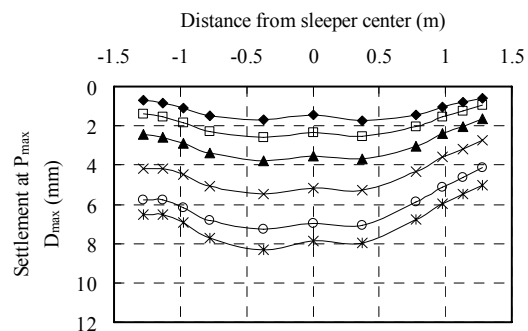

(h) $l=2.6 \mathrm{~m}, \mathrm{~h}_{\mathrm{S}}=195 \mathrm{~mm}$

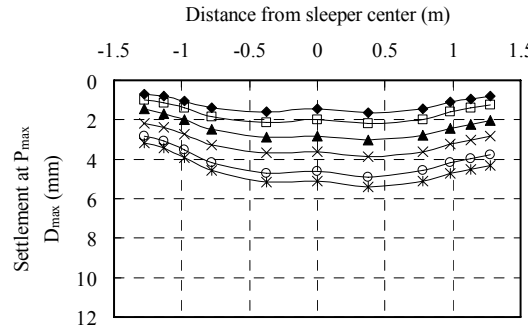

(i) $l=2.6 \mathrm{~m}, \mathrm{~h}_{\mathrm{S}}=260 \mathrm{~mm}$ 
$260 \mathrm{~mm}$, a differential settlement is caused at locations of both rails due to the increase of displacement amplitude at a sleeper end according with cyclic loading (Fig.10 (f) and Fig. 11 (f)).

\section{b) Difference in support condition of sleeper}

As mentioned above, the transit pattern in deflection shape of sleeper is different depending on a length and height of sleeper. Table 3 shows a classification for support conditions of sleeper after $2 \times 10^{5}$ cycles. To investigate why support conditions divide into a center support and a both ends support with cyclic loading, a displacement difference between a sleeper center and a sleeper end was plotted in an initial portion of cyclic loading for each sleeper shape as shown in Fig.12. When the displacement at a sleeper end is large in the initial portion of cyclic loading, it becomes a center support. On the other hand, it is found to become a both ends support when the displacement at a sleeper center is large.

\section{c) Separation of displacement amplitude of sleeper}

It is considered that only a sleeper of $l=2.3 \mathrm{~m}$ and $\mathrm{h}_{\mathrm{S}}=130 \mathrm{~mm}$ are almost supported by full contact on ballast up to $2 \times 10^{5}$ cycles. Sleepers except for it are considered to arise partially a clearance gap between a sleeper and ballast at a $\mathrm{P}_{\min }$ according with cyclic loading whereas there are full contacts in the initial portion of cyclic loading. It is

Table 3 Support condition of sleeper after $2 \times 10^{5}$ cycles

\begin{tabular}{|c|c|c|c|}
\hline$l(\mathrm{~m})$ & 130 & 200 & 260 \\
\hline 2.0 & Center & Center & Center \\
\hline 2.3 & Full & Both ends & Center \\
\hline 2.6 & Both ends & Both ends & Both ends \\
\hline
\end{tabular}

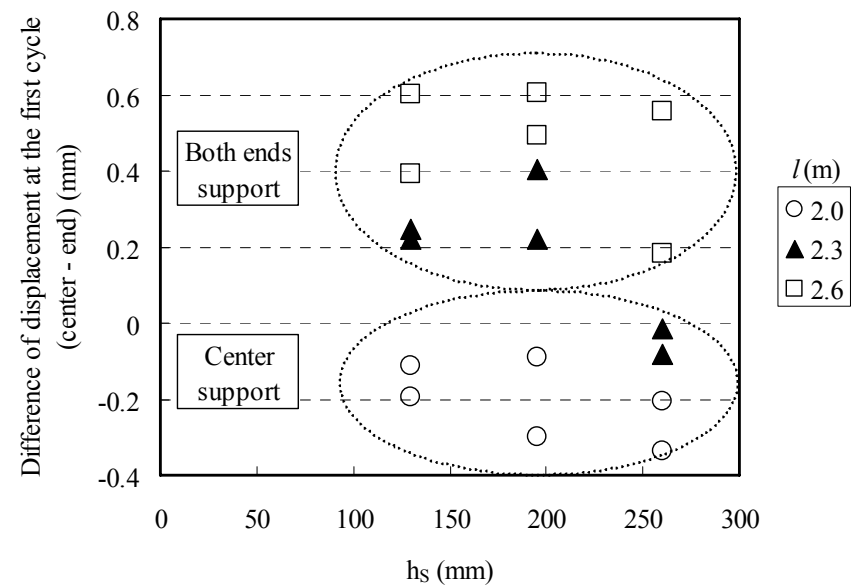

Fig. 12 Support condition of sleeper expected that the deformation behavior of ballast is different between full contact and partial contact according with cyclic loading. Then, a loading curve by a bi-linear type was assumed a load - displacement relationship as shown in Fig.13 in order to separate deformation behavior before and after the contact. The judgment of contact was defined as follows; since a displacement rate of sleeper in loading decrease rapidly at a location arising a clearance gap between a sleeper and ballast before and after the contact, a judgment of contact was determined at the time indicating a maximum displacement rate of sleeper. Moreover, it was referred to by a transition of a sleeper strain measured at the same time. A difference before the contact in displacement amplitude of sleeper, $\mathrm{D}_{\text {void, }}$ according with cyclic loading is shown in Fig. 14. A difference after the contact in displacement amplitude of sleeper, $\mathrm{D}_{\text {contact, }}$ according with cyclic loading is shown in Fig. 15. $D_{\text {void }}$ before the contact increases according with cyclic loading. On the other hand, it is found that $D_{\text {contact }}$ after the contact indicates almost a constant.

\section{d) Transition of settlement on cyclic loading test}

The transition for an amount of sleeper settlement $D_{\max }$ at a $P_{\max }$ is shown in Fig. 16. The transition of a differential settlement (irregularity of cross level) at a $\mathrm{P}_{\max }$ is shown in Fig. 17. Mean values of 2 measuring points at each rail were compared in both rails, and a lager value was plotted as $D_{\max }$ in Fig. 16. The differential settlement shown in Fig. 17 was plotted as an absolute value of the difference on an amount of settlement in both rails. The relation between sleeper shape and amount of settlement is not clear. It is found that the differential settlement of sleepers are large for $l=2.0 \mathrm{~m}$ in length, and for $l$ $=2.3 \mathrm{~m}$ in length and $\mathrm{h}_{\mathrm{S}}=260 \mathrm{~mm}$ in height becoming center support.

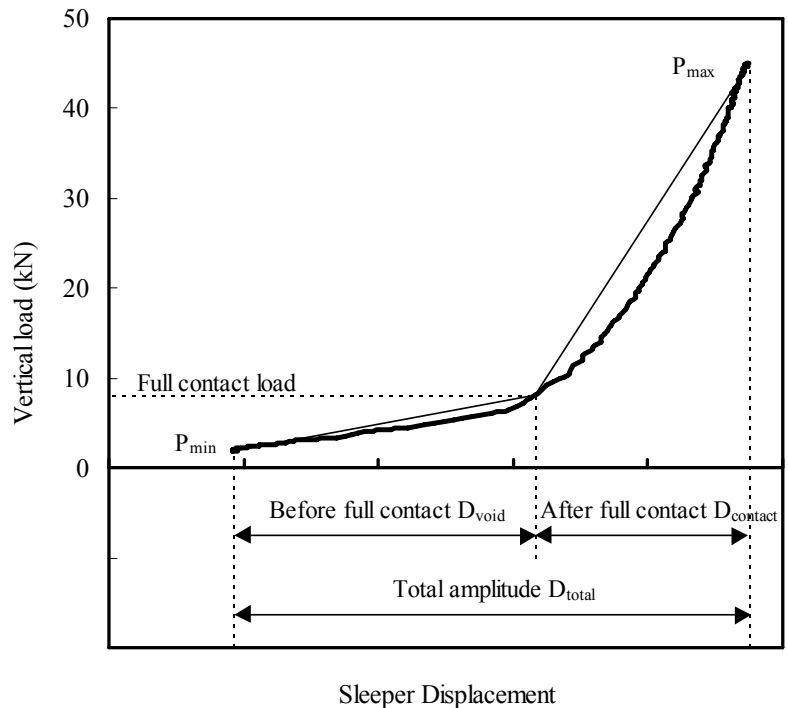

Fig. 13 Relation between load and sleeper displacement by bi-linear type 


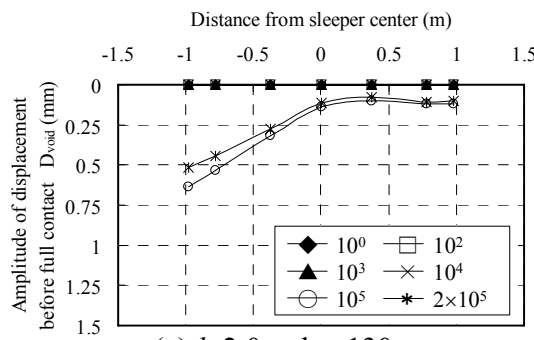

(a) $l=2.0 \mathrm{~m}, \mathrm{~h}_{\mathrm{S}}=130 \mathrm{~mm}$

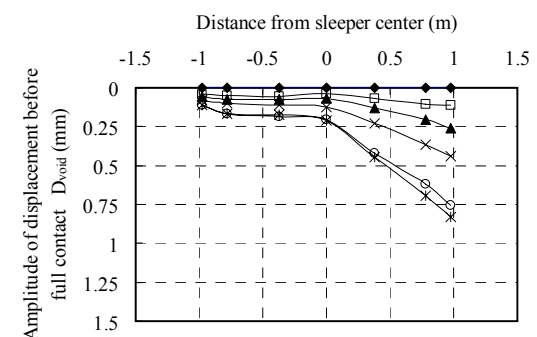

(b) $l=2.0 \mathrm{~m}, \mathrm{~h}_{\mathrm{S}}=195 \mathrm{~mm}$

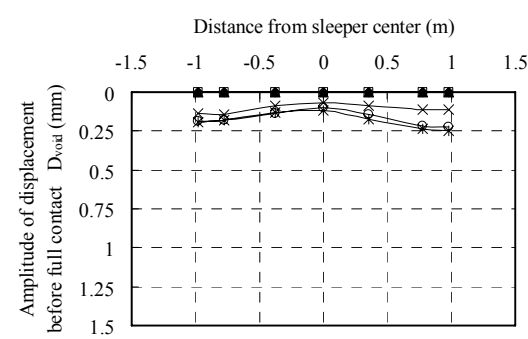

(c) $l=2.0 \mathrm{~m}, \mathrm{~h}_{\mathrm{S}}=260 \mathrm{~mm}$

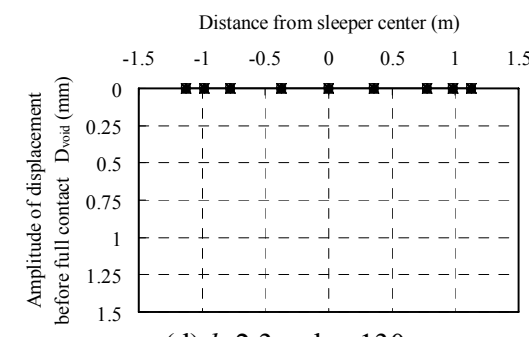

(d) $l=2.3 \mathrm{~m}, \mathrm{~h}_{\mathrm{S}}=130 \mathrm{~mm}$

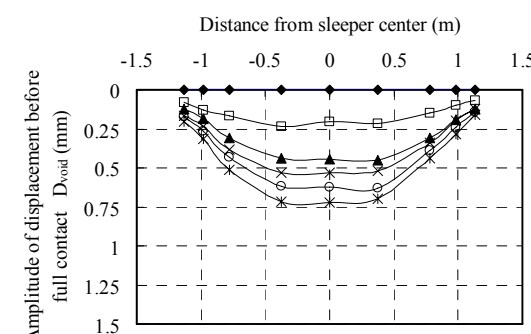

(e) $l=2.3 \mathrm{~m}, \mathrm{~h}_{\mathrm{S}}=195 \mathrm{~mm}$

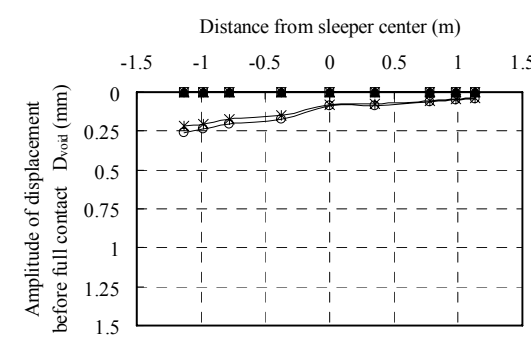

(f) $l=2.3 \mathrm{~m}, \mathrm{~h}_{\mathrm{S}}=260 \mathrm{~mm}$

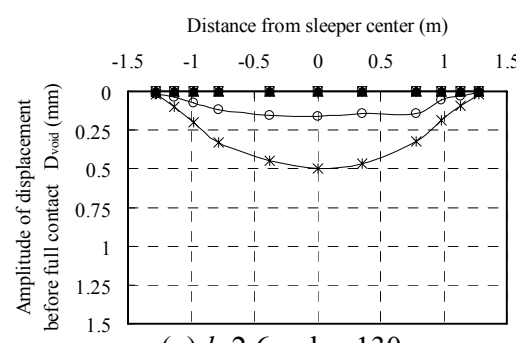

(g) $l=2.6 \mathrm{~m}, \mathrm{~h}_{\mathrm{S}}=130 \mathrm{~mm}$

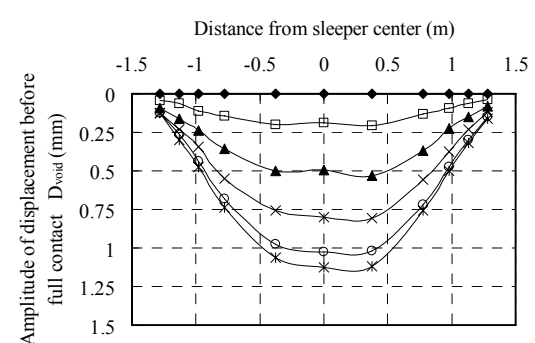

(h) $l=2.6 \mathrm{~m}, \mathrm{~h}_{\mathrm{S}}=195 \mathrm{~mm}$

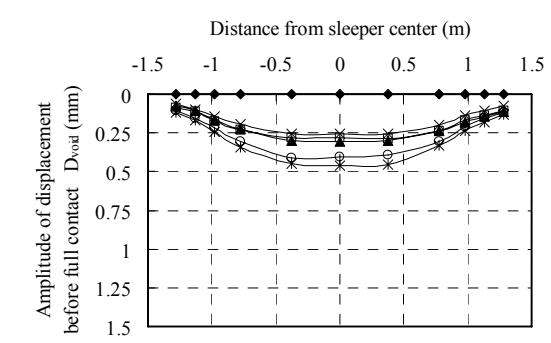

(i) $l=2.6 \mathrm{~m}, \mathrm{~h}_{\mathrm{S}}=260 \mathrm{~mm}$

Fig. 14 Transition of amplitude of displacement before full contact

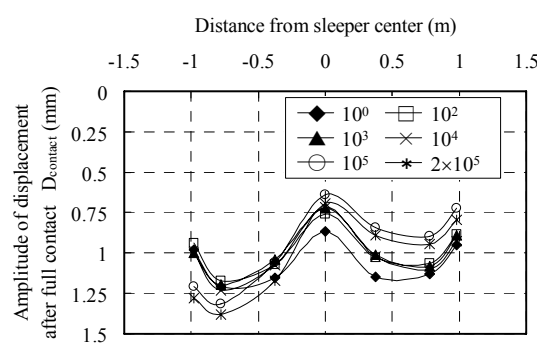

(a) $l=2.0 \mathrm{~m}, \mathrm{~h}_{\mathrm{S}}=130 \mathrm{~mm}$

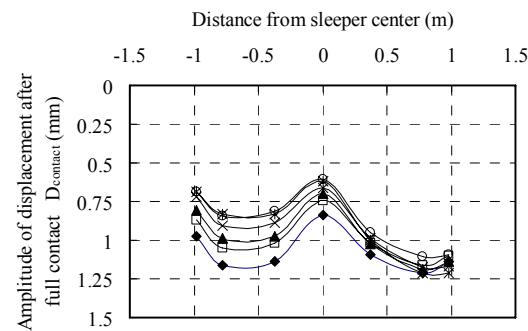

(b) $l=2.0 \mathrm{~m}, \mathrm{~h}_{\mathrm{S}}=195 \mathrm{~mm}$

Distance from sleeper center $(\mathrm{m})$

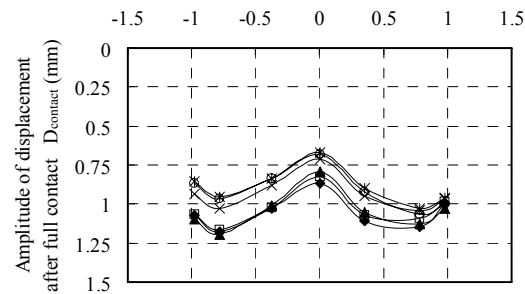

(c) $l=2.0 \mathrm{~m}, \mathrm{~h}_{\mathrm{S}}=260 \mathrm{~mm}$

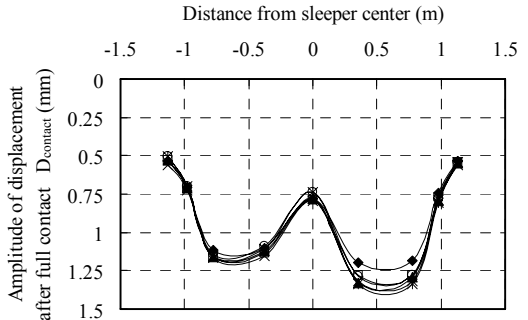

(d) $l=2.3 \mathrm{~m}, \mathrm{~h}_{\mathrm{S}}=130 \mathrm{~mm}$

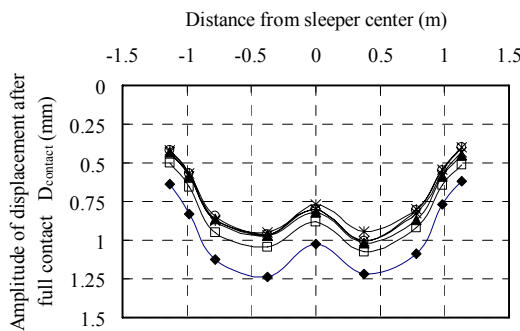

(e) $l=2.3 \mathrm{~m}, \mathrm{~h}_{\mathrm{S}}=195 \mathrm{~mm}$

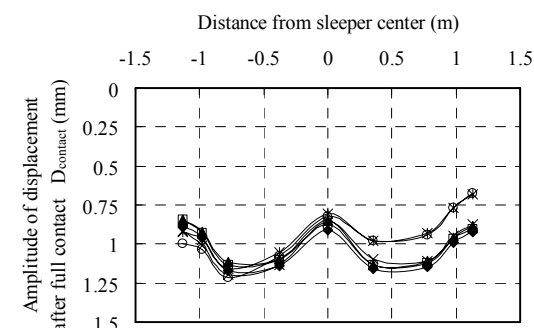

(f) $l=2.3 \mathrm{~m}, \mathrm{~h}_{\mathrm{S}}=260 \mathrm{~mm}$
Distance from sleeper center $(\mathrm{m})$

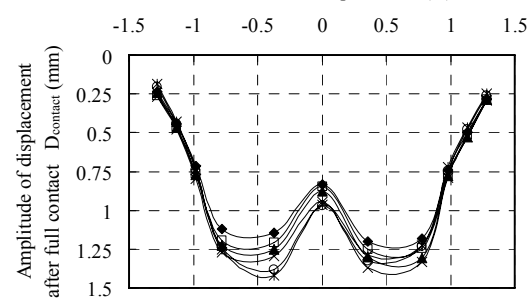

(g) $l=2.6 \mathrm{~m}, \mathrm{~h}_{\mathrm{S}}=130 \mathrm{~mm}$

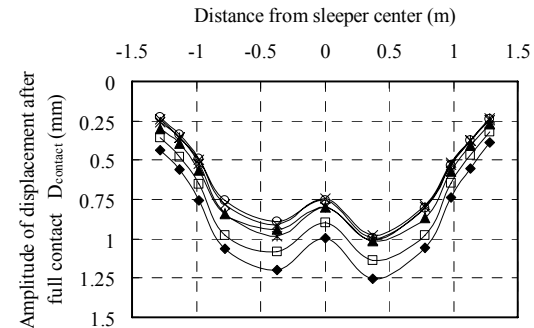

(h) $l=2.6 \mathrm{~m}, \mathrm{~h}_{\mathrm{S}}=195 \mathrm{~mm}$

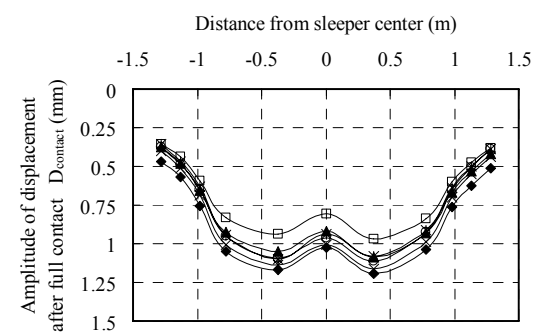

(i) $l=2.6 \mathrm{~m}, \mathrm{~h}_{\mathrm{S}}=260 \mathrm{~mm}$

Fig. 15 Transition of amplitude of displacement after full contact 


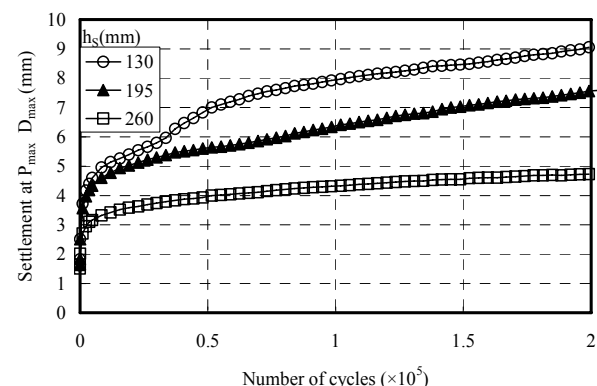

(a) $l=2.0 \mathrm{~m}$

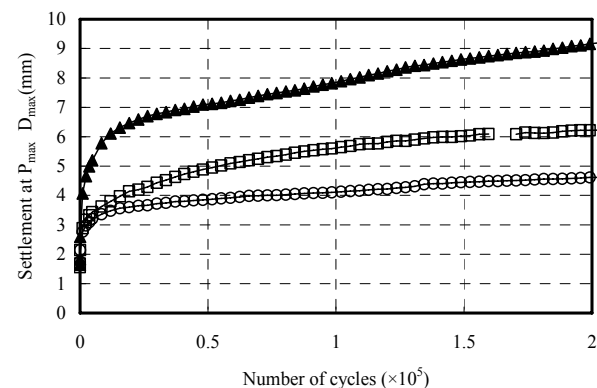

(b) $l=2.3 \mathrm{~m}$

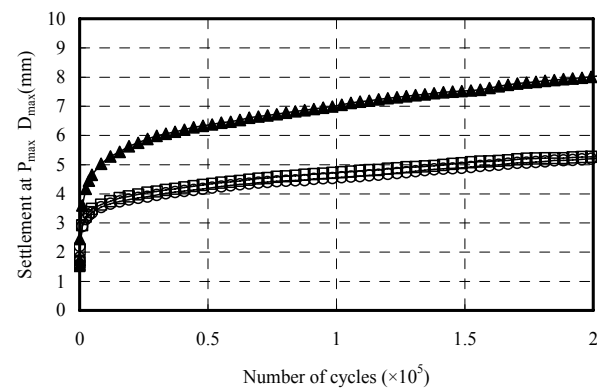

(c) $l=2.6 \mathrm{~m}$

Fig. 16 Transition ot sleeper settlement with cyclic loading

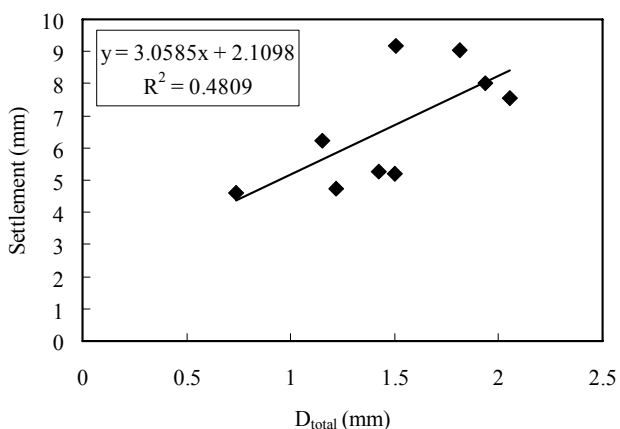

(a) Relation between $D_{\text {total }}$ and settlement

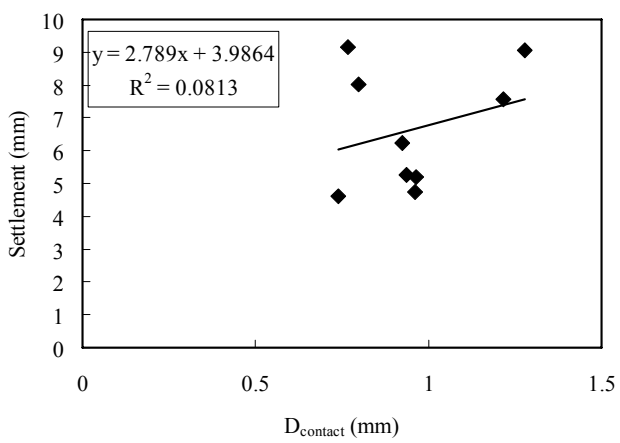

(c) Relation between $\mathrm{D}_{\text {contact }}$ and settlement

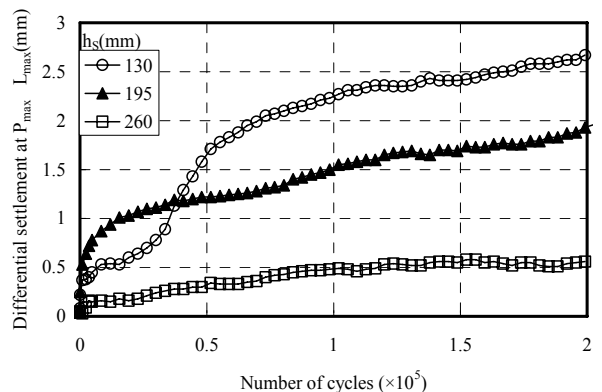

(a) $l=2.0 \mathrm{~m}$

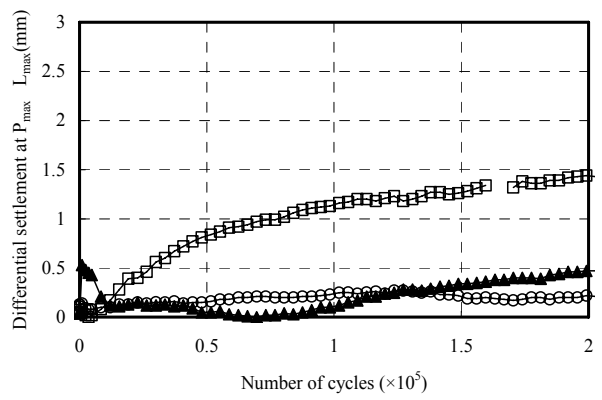

(b) $l=2.3 \mathrm{~m}$

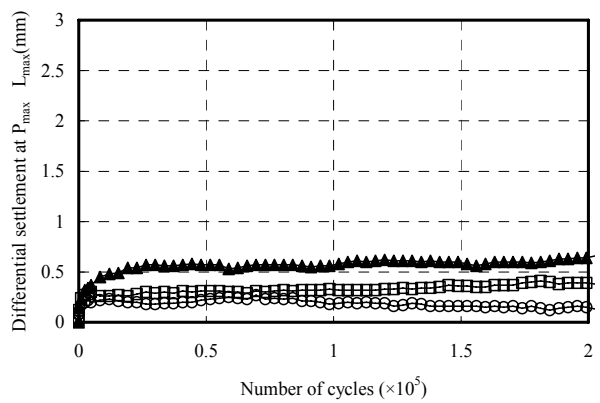

(c) $l=2.6 \mathrm{~m}$

Fig. 17 Transition of sleeper differential settlement with cyclic loading

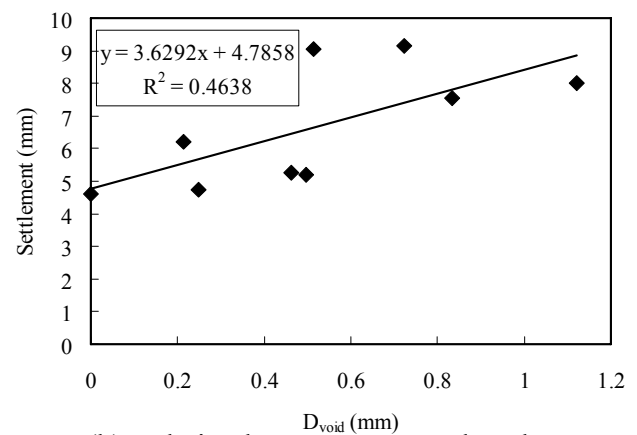

(b) Relation between $\mathrm{D}_{\text {void }}$ and settlement

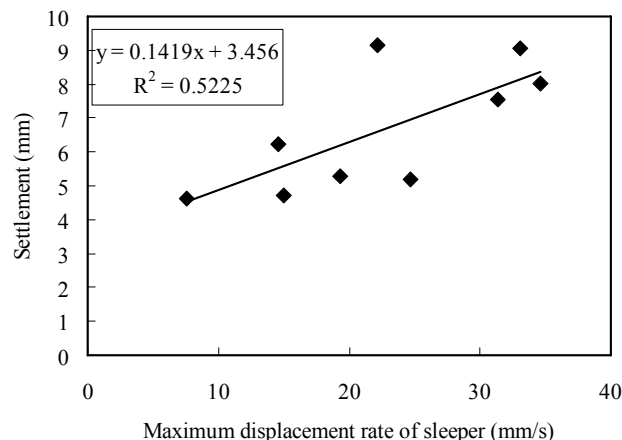

(d) Relation between maximum displacement rate of sleeper and settlement

Fig. 18 Relation between settlement and some factors 


\section{e) Extraction of factor affecting settlement}

In order to extract factors affecting amount of sleeper settlement, the relations are discussed among the amount of displacement amplitude of sleeper, $D_{\text {total }}, D_{\text {void }}$ and $D_{\text {contact }}$, after $2 \times 10^{5}$ cycles. And a relationship is investigated between maximum displacement rate of sleeper used to determine the contact and sleeper settlement $\mathrm{D}_{\max }$ after $2 \times 10^{5}$ cycles (Fig.18). For a cyclic loading in the state of full contact between a sleeper and ballast, the correlation is low between $\mathrm{D}_{\text {contact }}$ after the contact related to the settlement generally and the amount of settlement. On the other hand, it is found that the correlation is relatively high between $D_{\text {void }}$ indicating a clearance gap or maximum displacement rate of sleeper representing a collision rate of sleeper and amount of settlement.

\section{CONCLUSIONS}

Several types of sleeper of different lengths and heights were produced based on the results of $2 \mathrm{D}$ FE linear elastic analysis aimed at finding countermeasures to reduce track settlements due to cyclic loading in the ballasted track on the rigid roadbed for viaducts etc. A series of cyclic loading test were performed on a full-scale model track composed of produced sleeper, and the influence of the sleeper shape on cyclic deformation property of railway ballast was investigated.

The following conclusions can be derived from this study.

1) A support condition of sleeper is basically a center support for $2.0 \mathrm{~m}$ in length and both ends support for $2.6 \mathrm{~m}$ in length though the transit pattern in deflection shape of sleeper is different depending on lengths and heights of sleeper.

2) There is a possibility that the judgment whether becoming a center support according with cyclic loading or becoming both ends support is determined by means of the difference of sleeper displacement at the initial portion of cyclic loading.

3) The differential settlement shows the tendency to increase for the sleeper shape indicating a center support according with cyclic loading.

4) There is a possibility that the amount of sleeper settlement in the state where a clearance gap exists between a sleeper and ballast can be estimated by amount of displacement amplitude up to a full contact and a maximum displacement rate of sleeper.

\section{REFERENCES}

1) Uchida, M., Ishikawa, T., Namura, A., Takai, H., Miwa, M.: The Newly Designing Method of Ballasted Track Structure Considering Track Irregularity Growth, RTRI Report, Vol. 9, No. 4, pp.37-42, 1995.

2) Namura, A., Kohata, Y., Miura, S.: Deformation Properties of Railroad Ballast Subjected to Cyclic Loading and Evaluation Method, Journal of Applied Mechanics JSCE, Vol.5, pp.793-800, 2002.

3) Namura, A., Kohata, Y., Miura, S.: A prediction method for track settlement on the railroad ballast, Proceedings of 38th Annual Conference of the Japanese Geotechnical Society, 2003.

4) Sussmann, T.R., Ebersöhn, W., Selig, E.T.: Fundamental Nonlinear Track Load-Deflection Behaviour for Condition Evaluation, Transportation Research Record, 1742, pp.61-67, 2001.

5) Miura, I.: On design and Manufacture of Prestressed Concrete Ties, Railway Technical Research Report, No. 307, 1962.

6) JIS E 1201: Prestressed concrete sleepers - Pretensioning type, 1997.

7) Sekine, E., Kohata, Y., Jiang, G,. Yzaki, S., Nagato, H.: Strength and Deformation Characteristics of Railroad Ballast, RTRI Report, Vol. 14, No. 4, pp.13-18, 2000.

8) Ootsuka, M., Muramoto, K., Sekine, E.: An analysis on stress distribution of railroad roadbed under train load, Proceedings of 57th Annual Conference of the Japan Society of Civil Engineers, III-pp.1595-1596, 2002.

9) Sato, Y., Usami, T., Kobayashi, S., Sato, Y.: Development of "Ballast-Mat", Railway Technical Research Report, No. 866, 1973.

10) Nagafuji, T., Yoshida, H., Sakamoto, K.: Performance of Synthetic Sleeper in Practical Use, Railway Technical Research Pre-report, No. A-87-71, 1987.

(Received February 1, 2005) 